\title{
Effects of Openings in Shear Wall on Seismic Response of Structures
}

\author{
Sharmin Reza Chowdhury \\ Associate Professor, \\ Department of Civil Engineering \\ Ahsanullah University of \\ Science and Technology, \\ Dhaka-1208, Bangladesh
}

\author{
M.A. Rahman, M.J.Islam \\ Students, Department of Civil \\ Engineering, Ahsanullah \\ University of Science and \\ Technology, Dhaka-1208, \\ Bangladesh
}

\author{
A.K.Das \\ Student, Department of Civil \\ Engineering, Ahsanullah \\ University of Science and \\ Technology, Dhaka-1208, \\ Bangladesh
}

\begin{abstract}
Finite Element Modeling now a days is an essentital approach in analysisng and simulating civil engineering problem numerically. In this paper at attempt is made to apply the finite element modelling in analysing and exploring the behavior of shear wall with opening under seismis load actions. In modern tall buildings, shear walls are commonly used as a vertical structural element for resisting the lateral loads that may be induced by the effect of wind and earthquakes. Shear walls are generally located at the sides of buildings or arranged in the form of core that houses stairs and lifts. Due to functional requirements such as doors, windows, and other openings, a shear wall in a building contains many openings. The size and location of openings may vary from architectural and functional point of view. In most of the apartment building, size and location of openings in shear wall are made without considering its effect on structural behavior of the building. This study is carried out on 6- story frame-shear wall buildings, using linear elastic analysis with the help of finite element software, ETABS under earthquake loads in equivalent static analysis. The results reveal that stiffness as well as seismic responses of structures is affected by the size of the openings as well as their locations in shear wall. It is also explored that top lateral drift of the system can also be reduced thickening the element in the model around the opening of shear wall.
\end{abstract}

\section{Keywords}

Openings, Shear Wall, Drift, Earthquake Loads, Finite Element Analysis.

\section{INTRODUCTION}

A shear wall structure is considered to be one whose resistance to horizontal loading is provided entirely by shear walls (Smith and Coull, 1991[1]). An introduction of shear wall represents a structurally efficient solution to stiffen a building structural system because the main function of a shear wall is to increase the rigidity for lateral load resistance. Sometimes it is inevitable to have openings such as doors, windows, and other types of openings in shear wall. The size and location of openings may vary depending on purposes of the openings. In most of the apartment building, size and location of openings in shear wall are made without considering its effect on structural behavior of the building. Shear wall with openings using brick element and super elements were described in number of papers (Husain MA, 2011[2], Kim and Lee, 2003[3]). Lin and Kuo, 1988[4] conducted finite element analysis and experimental work to study the ultimate strength of shear wall with openings under lateral load. The test program demonstrated the shear behavior of reinforced concrete walls with different sizes of opening and reinforcing patterns around the opening. The test results indicated that the shear strength contributed by diagonal reinforcement around opening reached $40 \%$ of its yield strength, while the shear strength contributed by rectangular arrangement reached $20 \%$ of its yield strength. It was also concluded that shear capacity of section is not only affected by width of opening but also affected by depth of opening as well. Kim and Lee, 2003[3] proposed a method for the analysis of shear wall with openings using super elements to model the shear wall. Qaqish and Daqqaq, 2000[5] studied on effect of small openings on behavior of shear walls and the effect of opening size on behavior of coupled shear walls. Yanez, Park and Paulay, 1992[6] studied on seismic behavior of reinforced concrete walls with square openings of different size and arrangement under reversed cyclic loading. It was concluded that the stiffness of walls is dependent on the size of the openings not on their horizontal locations. It was suggested that the stiffness of walls without openings can be used for the stiffness of the walls with openings smaller than $10 \%$ of the wall area.

In this study linear static analysis is performed on 6 story frame shear wall building keeping opening in shear wall (shell element is used to represent shear wall) with finite element software, ETABS[7] under earthquake loads in equivalent static method. The objective of this study is to know the effects of openings sizes and configurations in shear wall on stiffness as well as on seismic responses and explore the behavior of structural system so that a suitable configuration of openings in shear walls can be obtained.

\section{MODELING OF STRUCTURE}

6 story, $7 \times 3$ bays frame-shear wall buildings with $3 \mathrm{~m}$ span and floor height of 3 meters, using linear elastic analysis with the help of finite element software ETABS under earthquake loads in equivalent static method is set for this study. Typical floor plan (Fig. 1 a) with same dimensions $21 \mathrm{~m} \times 9 \mathrm{~m}$ is used for all model buildings. Shear wall thickness is taken as 203 $\mathrm{mm}$. Shell Element is used to represent the shear wall. The sizes of beams, columns and slabs are $254 \mathrm{~mm} \times 457 \mathrm{~mm}$, $254 \mathrm{~mm} \times 457 \mathrm{~mm}$ and $127 \mathrm{~mm}$ respectively. 3D view of building with shear wall openings as shown in ETABS is shown in Fig. 1(b). The Earthquake load is applied as per BNBC,1993[8] considering zone coefficient 1.5, and structural importance factor 1 . 


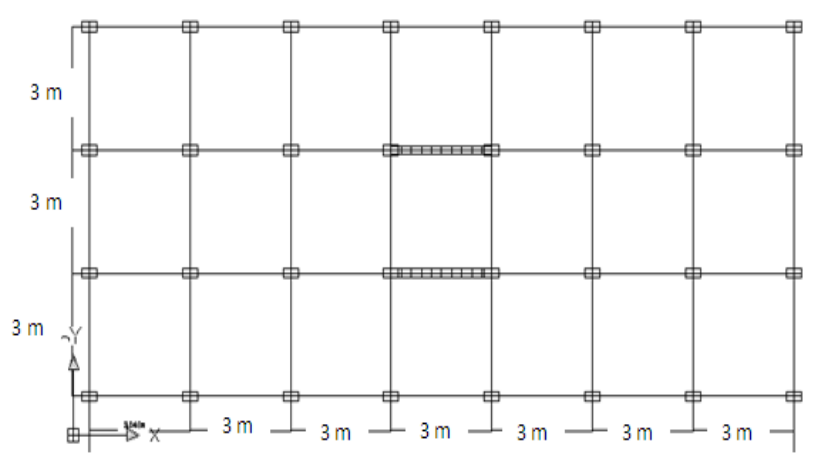

(a) Plan View of the Building

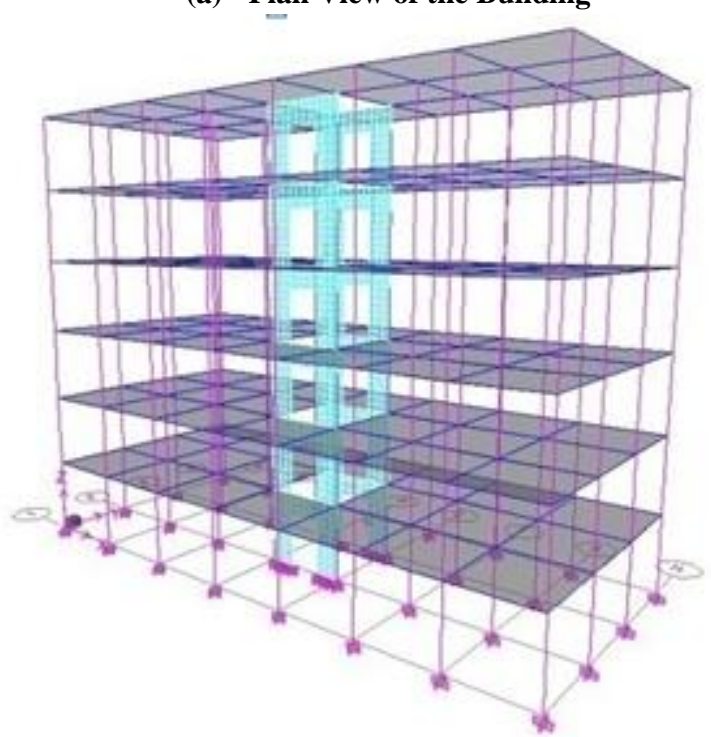

(b) View from ETABS

Fig 1: Frame-Shear Wall Structure set for this study

\section{PROBLEM STATEMENT}

General problem selected for this study is shown in Figure 1. Analysis is divided into two main parts; Analysis regarding shear wall placed in-plane of loading and analysis regarding shear wall placed at out of plane of loading. As we know that structural behavior regarding in-plane of loading is much more important than that of out of plane of loading, most of the discussions are concerned in this study with openings in shear wall placed in-plane of loading. Door opening (at each floor) in shear wall are kept $0.9 \mathrm{~m} \times 2.2 \mathrm{~m}$ and window opening are maintained two sizes $(1.2 \mathrm{~m} \times 1.2 \mathrm{~m}$ and $1.8 \times 1.8 \mathrm{~m})$ as usual practice in building structure. Window opening are made at the centre of shear wall where as door opening are varied as left, centre and right of the shear wall. Stiffening of the shear wall around the opening is represented by thickening $305 \mathrm{~mm}$ width of shear wall around the opening and the thickness of this stiffening part is $50 \mathrm{~mm}$ more than the remaining part of the shear wall.

\section{RESULTS AND DISCUSSION 4.1 Opening Locations}

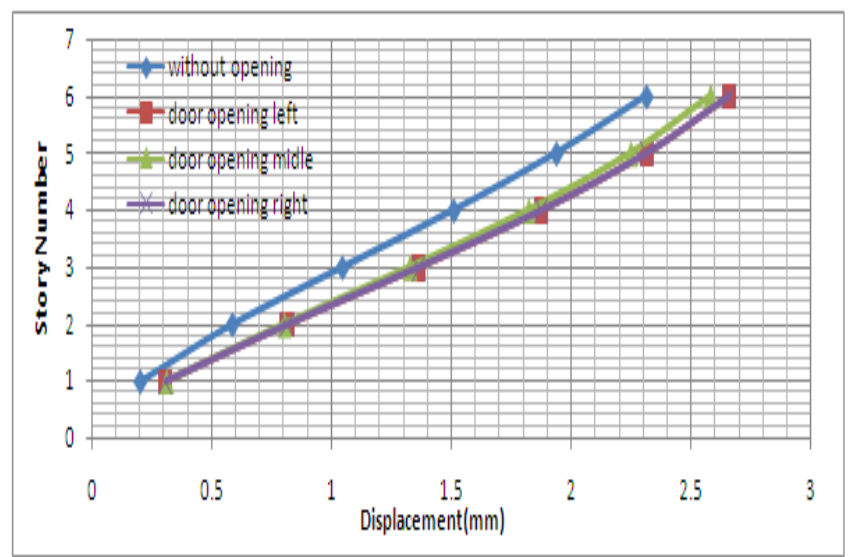

Fig 2: Comparison of displacement between shear wall without opening and shear wall with door-opening at different locations

Figure 2 shows the comparison of displacements at different story levels of the 6 storied building between when there will be no opening in shear wall and when there will be openings for doors exist at left, centre and right end of the shear wall. At 1st story level, displacements are almost equal but as soon as story level increases, displacements are increasing for buildings of shear wall with opening for door. At topmost story level, displacement for shear wall with opening at middle is little bit less than that of shear wall with openings placed at left or right.

\subsection{Opening Size}

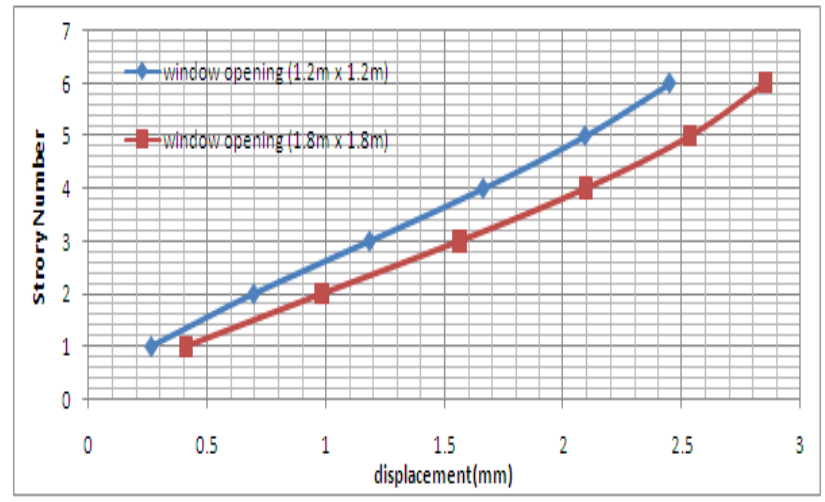

Fig 3: Variation of displacement with story number for different opening sizes

Figure 3 shows the variation of displacement at different story levels with story number when there will be different opening sizes $(1.2 \mathrm{~m} \times 1.2 \mathrm{~m}$ and $1.8 \mathrm{~m} \times 1.8 \mathrm{~m})$ are kept in shear wall for window purpose. It is clearly shown from this figure that more the area of opening more the displacements conceded by the building and this trend increases with story level. 


\section{STIFFENING THE PERIPHERY OF THE OPENING}

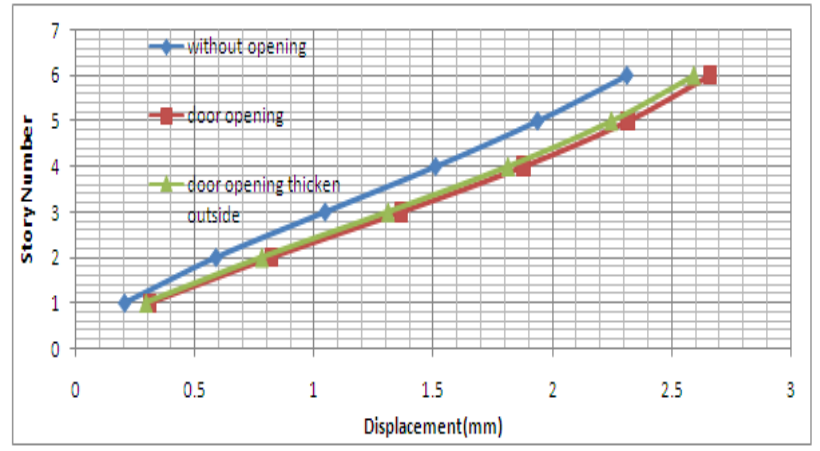

Fig 4: Variation of displacement with story number for door opening with and without stiffening

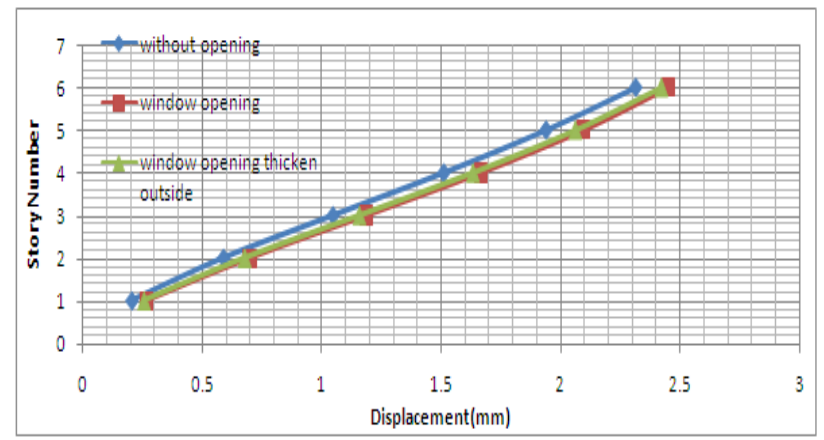

Fig 5: Variation of displacement with story number for window opening with and without stiffening

Figures 4 and 5 show the effect of stiffening around the opening for share wall with door and window opening on displacement at different story levels respectively. $1.8 \mathrm{~m} \mathrm{x}$ $1.8 \mathrm{~m}$ window opening sizes and door openings at left or right are used for this analysis. It is concluded from these figures that thickening wall around the door openings are more effective than that of window opening since displacement is reduced more at top most story level for shear wall with door opening.

\section{SHEAR WALL OUT OF PLANE OF LOADING}

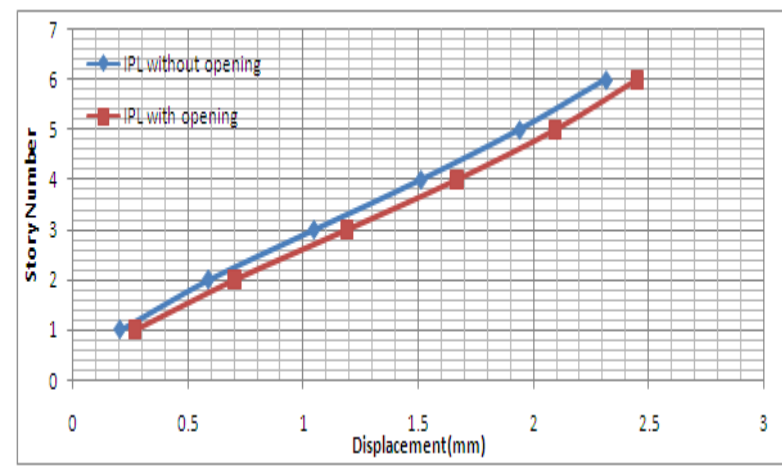

Fig 6: Variation of displacement with story number for opening at in-plane of loading.

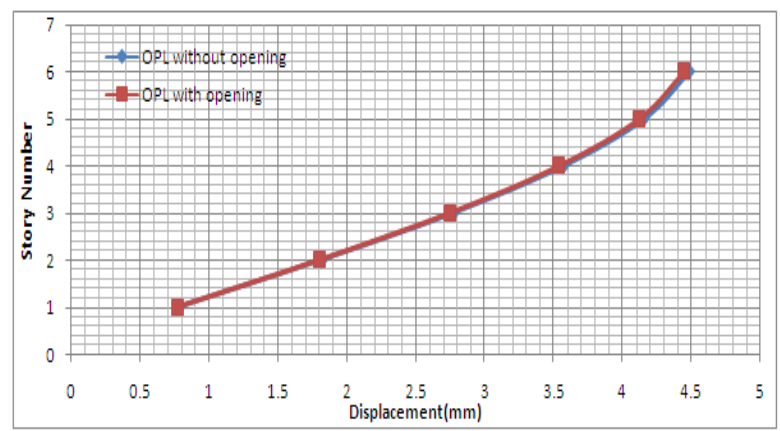

Fig 7: Variation of displacement with story number for opening at out of plane of loading.

Figures 6 and 7 depict the variation of displacement with story number when opening in shear wall placed in-plane of loading (IPL) and when opening in shear wall placed out of plane of loading (OPL). From these figures it is clearly understood that opening in shear wall placed in plane of loading is more critical than that of opening in shear wall placed out of plane of loading since there is a significant change in displacement noticed after having opening in shear wall placed in plane of loading.

\section{CONCLUSIONS}

With the application of finite element approach using software, ETABS this study reveals that stiffness as well as seismic responses of structures is affected by the size of the openings as well as their locations in shear wall. It is advisable to say that before introducing opening in shear wall proper analysis should be made. It is also concluded that more the area of opening more the displacements conceded by the building and this trend increases with increasing story level. Thickening wall around the door openings are more effective than that of window opening as far as displacement is concerned at top most story level. Furthermore, it is clearly understood that opening in shear wall placed in plane of loading is more critical than that of opening in shear wall placed out of plane of loading since there is a significant change in displacement noticed after having opening in shear wall placed in plane of loading. Shear wall with different opening sizes and locations considering coupling beam actions may be considered for future research. Also nonlinear dynamic analysis is required to make comprehensive comments.

\section{REFERENCES}

[1] Smith, BS and Coull, A. 1991.Tall Building Structures, John Wiley and Sons, Inc.

[2] Husain, MA, 2011. Analysis of Shear Wall with Openings using Brick Element, European Journal of Scientific Research, ISSN 1450-216X, Vol. 51, No. 3, pp. 359-371.

[3] Kim HS. and Lee DG. 2003. Analysis of shear wall with openings using super elements, Engineering Structures, 25:981-991. 
International Journal of Computer Applications (0975 - 8887)

Volume 59-No.1, December 2012

[4] Lin, C.Y. and C.L. Kuo. 1988. Behavior of shear wall with openings. Proceedings of Ninth world Conference on Earthquake Engineering. Tokyo-Kyoto, Japan, IV: 535-540.

[5] Qaqish, S. and F. Daqqaq. 2000. Effect of horizontal forces on shear walls with small openings. Technical Services and Studies-University of Jordan. Jordan

[6] Yanez, F.V., R. Park and T. Paulay. 1992. Seismic behavior of walls with irregular openings. Earthquake
Engineering. Tenth World Conference, Balkema, Rotterdam.

[7] ETABS Nonlinear Version 9.6.0.1995. Extended 3-D analysis of Building Systems. California; Computers and Structures Inc. Berkeley

[8] Bangladesh National Building Code (BNBC), 1993. 